Polymer Journal, Vol. 38, No. 9, pp. 983-988 (2006)

(C) 2006 The Society of Polymer Science, Japan

\title{
The Attractive Gauche Effect of Ethylene Oxides
}

\author{
Yuji SASANUMA ${ }^{\dagger}$ and Kentaro Sugita \\ Department of Applied Chemistry and Biotechnology, Faculty of Engineering, Chiba University, \\ 1-33 Yayoi-cho, Inage-ku, Chiba 263-8522, Japan
}

(Received May 1, 2006; Accepted July 4, 2006; Published August 18, 2006)

\begin{abstract}
Conformational energies of monomeric (1,2-dimethoxyethane, DME) and trimeric (triglyme) model compounds of poly(ethylene oxide) have been evaluated by accurate ab initio molecular orbital (MO) calculations at the MP2/6-311++G(3df, 3pd)//HF/6-31G(d) level. The first-order interaction energies ( $E_{\sigma}$ 's) for gauche states around the $\mathrm{C}-\mathrm{C}$ bonds of $\mathrm{DME}$ and the terminal repeating unit of triglyme are $c a .+0.1 \mathrm{kcal} \mathrm{mol}^{-1}$, whereas the central unit of triglyme has a slightly negative $E_{\sigma}$ value of $c a .-0.1 \mathrm{kcal} \mathrm{mol}^{-1}$. For the $\mathrm{C}-\mathrm{C}$ bond conformations of triglyme, the MO calculations exactly agree with NMR observations using a nonpolar solvent of cyclohexane- $d_{12}$. The attractive gauche effect of the ethylene oxides has been shown to exist independently of intramolecular $(\mathrm{C}-\mathrm{H}) \cdots \mathrm{O}$ hydrogen bonds. [doi:10.1295/polymj.PJ2006018]

KEY WORDS Poly(ethylene oxide) / Conformation / Ab Initio Molecular Orbital Calculation / NMR / Attractive Gauche Effect / Weak Hydrogen Bond /
\end{abstract}

The attractive gauche effect has been found in $\mathrm{X}-$ $\mathrm{C}-\mathrm{C}-\mathrm{X}$ bond sequences, where $\mathrm{X}$ stands for electronegative atoms such as $\mathrm{F}, \mathrm{Cl}$, and $\mathrm{O} ;{ }^{1,2}$ the central $\mathrm{C}-\mathrm{C}$ bond has been considered to have the inherent gauche preference. In a previous paper, ${ }^{3}$ we have proposed a concept of the competitive balance between intramolecular and intermolecular attractions of ethylene oxides. The isolated (i.e., gaseous) ethylene-oxide chains form the intramolecular hydrogen bonds, which cause an apparent gauche stability of the $\mathrm{C}-\mathrm{C}$ bond. In polar solvents, however, the $\mathrm{O}-\mathrm{C}-\mathrm{C}-\mathrm{O}$ segment tends to prefer the tgt conformation because of attractive interactions with solvents (for the bond sequence, see Figure 1). These phenomena may be observed as variations in two conformational energies: $E_{\sigma}$ and $E_{\omega}$ (for the interactions, see Figure 2). The former energy corresponds to the energy difference between trans and gauche states, and the latter represents the $(\mathrm{C}-\mathrm{H}) \cdots \mathrm{O}$ interaction. The $E_{\sigma}$ and $E_{\omega}$ values, depending on the polarity of environment, shift in the

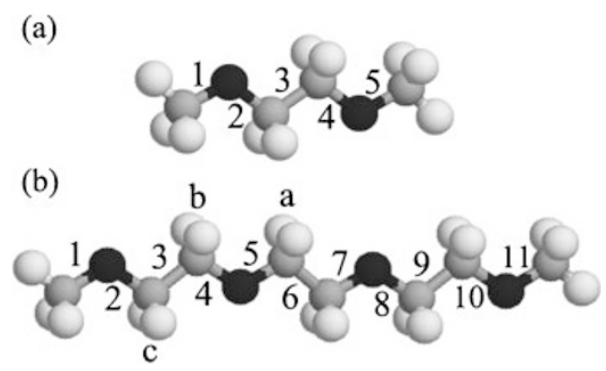

Figure 1. (a) Monomeric (1,2-dimethoxyethane: DME) and (b) trimeric (triglyme) model compounds of poly(ethylene oxide) (PEO). As indicated, the skeletal bonds are numbered. opposite directions: $E_{\sigma}=+0.32$ and $E_{\omega}=-1.12$ $\mathrm{kcal} \mathrm{mol}^{-1}$ for 1,2-dimethoxyethane (DME) in the gas phase ${ }^{3} E_{\sigma}=-0.25$ and $E_{\omega}=-0.79 \mathrm{kcal} \mathrm{mol}^{-1}$ for poly(ethylene oxide) (PEO) in weakly polar solvents such as 1,4-dioxane and benzene $;^{3} E_{\sigma}=-0.5$

(a)

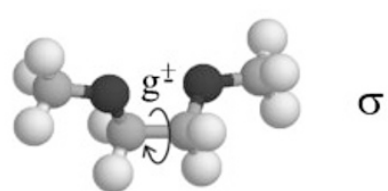

(b)

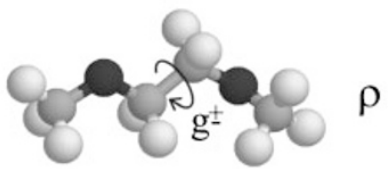

(c)

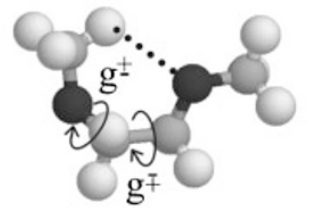

$\omega$

(d)

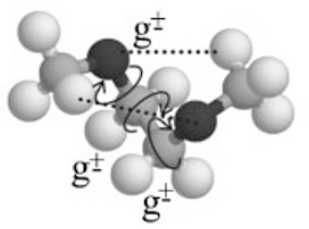

$\chi$

Figure 2. Intramolecular interactions defined for the ethylene oxides: (a) $\sigma$ and (b) $\rho$ : the first-order interactions around the $\mathrm{C}-\mathrm{C}$ and $\mathrm{C}-\mathrm{O}$ bonds, respectively; (c) $\omega$ : the second-order interaction occurring in $\mathrm{g}^{ \pm} \mathrm{g}^{\mp}$ conformations for the $\mathrm{C}-\mathrm{O} / \mathrm{C}-\mathrm{C}$ bond pair; (d) $\chi$ : the third-order interaction formed in $\mathrm{g}^{ \pm} \mathrm{g}^{ \pm} \mathrm{g}^{ \pm}$conformations of the $\mathrm{O}-\mathrm{C}-\mathrm{C}-\mathrm{O}$ bond sequence. The $\omega$ and $\chi$ interactions represent intramolecular hydrogen bonds. The model here is DME.

${ }^{\dagger}$ To whom correspondence should be addressed (Tel: +81-43-290-3394, Fax: +81-43-290-3394, E-mail: sasanuma@ faculty.chiba-u.jp). 
and $E_{\omega}=+0.4 \mathrm{kcal} \mathrm{mol}^{-1}$ for PEO in the $\Theta$ solutions, e.g., $0.45 \mathrm{M} \mathrm{K}_{2} \mathrm{SO}_{4}$ at $34.5^{\circ} \mathrm{C} .{ }^{4-6} \mathrm{In}$ a good solvent, water, PEO shows a very small $E_{\sigma}$ value of -1.2 $\mathrm{kcal} \mathrm{mol}^{-1}{ }^{7}$ The interdependence of the two conformational energies has so far been pointed out. ${ }^{8-10}$

The natural bond orbital (NBO) analysis ${ }^{11}$ on DME indicated that the attractive gauche effect comes mainly from $\mathrm{C}-\mathrm{H}$ bond $\rightarrow \mathrm{C}-\mathrm{O}$ antibond $\left(\sigma_{\mathrm{C}-\mathrm{H}} \rightarrow \sigma_{\mathrm{C}-\mathrm{O}}^{*}\right)$ delocalizations, ${ }^{3}$ suggesting that the tgt state is more stable than $\mathrm{ttt}$. Here, the designation tgt indicates that bonds 2,3 , and 4 take $\mathrm{t}, \mathrm{g}$, and $\mathrm{t}$ states, respectively (see Figure 1a). To our knowledge, however, all $a b$ initio molecular orbital (MO) calculations performed so far for DME have suggested that the ttt conformation is more stable than tgt. In the crystalline state, PEO is allowed to adopt either tgt or ttt state in the $\mathrm{O}-\mathrm{C}-\mathrm{C}-\mathrm{O}$ bonds. The former and latter conformations form a distorted $(7 / 2)$ helix ${ }^{12,13}$ and a planar zigzag structure, ${ }^{14}$ respectively. It is expected that PEO prefers the tgt state to ttt, because the ttt conformation is formed only in stretched samples. ${ }^{14,15}$ The four $(7 / 2)$ helical chains form a $P 2_{1} / a$ monoclinic cell, ${ }^{13}$ in which we can not find any clue to the specific interactions such as $\mathrm{O} \cdots \mathrm{H}$ close contacts to stabilize the tgt conformation.

In the previous study, ${ }^{3}$ we calculated conformer free energies of monomer (DME) and trimer (triglyme) of PEO at the B3LYP/6-311+G(3df, 2p)// $\mathrm{B} 3 \mathrm{LYP} / 6-31 \mathrm{G}(\mathrm{d})$ level. The gauche energy of the central $\mathrm{C}-\mathrm{C}$ bond seems to depend on the chain length: DME, $0.76 \mathrm{kcal} \mathrm{mol}^{-1}$; triglyme, $0.15 \mathrm{kcal} \mathrm{mol}^{-1}$. It is known that more expensive MO calculations based on the MP2 theory yield more reliable energy data than the B3LYP computations. Therefore, accurate MO calculations at the MP2/6-311++G(3df, 3pd)// $\mathrm{HF} / 6-31 \mathrm{G}(\mathrm{d})$ level have been carried out here for triglyme as well as DME. In addition, we have analyzed ${ }^{1} \mathrm{H}$ NMR spectra observed from triglyme to evaluate the bond conformations and compare the MO calculations. If gaseous triglyme has $E_{\sigma}$ values significantly smaller than hydrocarbon chains such as $n$-alkanes and polyethylene, the attractive gauche effect would be proved to exist independently of the $(\mathrm{C}-\mathrm{H}) \cdots \mathrm{O}$ hydrogen bonds as predicted by the NBO analysis.

\section{COMPUTATIONS AND EXPERIMENTS}

\section{Ab Initio MO Calculations}

$A b$ initio MO calculations were carried out for DME and triglyme with the Gaussian03 program $^{16}$ installed on an HPC Silent-SCC T2 computer. For each conformer, the geometrical parameters were fully optimized at the HF/6-31G(d) level, and the thermal correction to the Gibbs free energy (at $25^{\circ} \mathrm{C}$ and $1 \mathrm{~atm})$ was calculated with a calibration factor of
$0.9135 .{ }^{17}$ With the optimized geometry, the selfconsistent field (SCF) energy was computed at the MP2/6-311++G(3df, 3pd) level. All the SCF calculations were performed under the tight convergence. The Gibbs free energy was calculated from the SCF and thermal-correction energies, being given here as the difference from that of the all-trans conformer and denoted as $\Delta G_{k}$ ( $k$ : conformer number).

\section{NMR Measurements of Triglyme}

Commercially available triglyme was used without further purification. Cyclohexane- $d_{12}$, chloroform- $d$, methanol- $d_{4}$, dimethyl sulfoxide- $d_{6}$, and deuterium oxide were used as the solvents, and the solute concentration was $c a .5 \mathrm{vol} \%$. The proton NMR spectra were measured at $500 \mathrm{MHz}$ on a JEOL JNM-LA500 spectrometer equipped with a variable temperature controller in the Chemical Analysis Center of Chiba University. During the measurement the probe temperature was maintained within $\pm 0.1^{\circ} \mathrm{C}$ fluctuations. The $\pi / 2$ pulse width, data acquisition time, and recycle delay were $5.6 \mu \mathrm{s}, 13.1 \mathrm{~s}$, and $3.7 \mathrm{~s}$, respectively. Before the Fourier transform, zero filling was performed so that the digital resolution would be close to $0.01 \mathrm{~Hz}$.

\section{RESULTS AND DISCUSSION}

\section{MO Calculations}

Statistical weight matrices $U_{i}$ ( $i$ : bond number) of DME and triglyme are given by

$$
\begin{gathered}
U_{2}=\left[\begin{array}{ccc}
1 & \rho_{2} & \rho_{2} \\
0 & 0 & 0 \\
0 & 0 & 0
\end{array}\right] \\
U_{3}=\left[\begin{array}{ccccccccc}
1 & \sigma_{3} & \sigma_{3} & 0 & 0 & 0 & 0 & 0 & 0 \\
0 & 0 & 0 & 1 & \sigma_{3} & \sigma_{3} \omega_{3} & 0 & 0 & 0 \\
0 & 0 & 0 & 0 & 0 & 0 & 1 & \sigma_{3} \omega_{3} & \sigma_{3}
\end{array}\right]
\end{gathered}
$$

$$
\begin{aligned}
& U_{4}=U_{7}=U_{10}= \\
& {\left[\begin{array}{ccccccccc}
1 & \rho_{i} & \rho_{i} & 0 & 0 & 0 & 0 & 0 & 0 \\
0 & 0 & 0 & 1 & \rho_{i} & \rho_{i} \omega_{i} & 0 & 0 & 0 \\
0 & 0 & 0 & 0 & 0 & 0 & 1 & \rho_{i} \omega_{i} & \rho_{i} \\
1 & \rho_{i} & \rho_{i} & 0 & 0 & 0 & 0 & 0 & 0 \\
0 & 0 & 0 & 1 & \rho_{i} \chi_{i} & \rho_{i} \omega_{i} & 0 & 0 & 0 \\
0 & 0 & 0 & 0 & 0 & 0 & 1 & 0 & \rho_{i} \\
1 & \rho_{i} & \rho_{i} & 0 & 0 & 0 & 0 & 0 & 0 \\
0 & 0 & 0 & 1 & \rho_{i} & 0 & 0 & 0 & 0 \\
0 & 0 & 0 & 0 & 0 & 0 & 1 & \rho_{i} \omega_{i} & \rho_{i} \chi_{i}
\end{array}\right]}
\end{aligned}
$$




$$
U_{5}=U_{8}=
$$

$$
\left[\begin{array}{ccccccccc}
1 & \rho_{i} & \rho_{i} & 0 & 0 & 0 & 0 & 0 & 0 \\
0 & 0 & 0 & 1 & \rho_{i} & \rho_{i} \omega_{i}^{\prime} & 0 & 0 & 0 \\
0 & 0 & 0 & 0 & 0 & 0 & 1 & \rho_{i} \omega_{i}^{\prime} & \rho_{i} \\
1 & \rho_{i} & \rho_{i} & 0 & 0 & 0 & 0 & 0 & 0 \\
0 & 0 & 0 & 1 & \rho_{i} & \rho_{i} \omega_{i}^{\prime} & 0 & 0 & 0 \\
0 & 0 & 0 & 0 & 0 & 0 & 1 & 0 & \rho_{i} \\
1 & \rho_{i} & \rho_{i} & 0 & 0 & 0 & 0 & 0 & 0 \\
0 & 0 & 0 & 1 & \rho_{i} & 0 & 0 & 0 & 0 \\
0 & 0 & 0 & 0 & 0 & 0 & 1 & \rho_{i} \omega_{i}^{\prime} & \rho_{i}
\end{array}\right]
$$

and

$$
\begin{aligned}
& U_{6}=U_{9}= \\
& {\left[\begin{array}{ccccccccc}
1 & \sigma_{i} & \sigma_{i} & 0 & 0 & 0 & 0 & 0 & 0 \\
0 & 0 & 0 & 1 & \sigma_{i} & \sigma_{i} \omega_{i} & 0 & 0 & 0 \\
0 & 0 & 0 & 0 & 0 & 0 & 1 & \sigma_{i} \omega_{i} & \sigma_{i} \\
1 & \sigma_{i} & \sigma_{i} & 0 & 0 & 0 & 0 & 0 & 0 \\
0 & 0 & 0 & 1 & \sigma_{i} & \sigma_{i} \omega_{i} & 0 & 0 & 0 \\
0 & 0 & 0 & 0 & 0 & 0 & 1 & 0 & \sigma_{i} \\
1 & \sigma_{i} & \sigma_{i} & 0 & 0 & 0 & 0 & 0 & 0 \\
0 & 0 & 0 & 1 & \sigma_{i} & 0 & 0 & 0 & 0 \\
0 & 0 & 0 & 0 & 0 & 0 & 1 & \sigma_{i} \omega_{i} & \sigma_{i}
\end{array}\right]}
\end{aligned}
$$

Here, the conformational energies, $E_{\xi_{i}},\left(\xi_{i}=\rho_{i}, \sigma_{i}, \omega_{i}\right.$, and $\chi_{i}$ ), have been defined for each bond to examine their position dependence. The intramolecular interactions are illustrated in Figure 2. Tables I and II show the SCF and Gibbs free energies of the individual conformers of DME and triglyme, respectively. In the rotational isomeric state (RIS) scheme, ${ }^{5,18}$ the $\Delta G_{k}$ values of DME are represented as a function of $E_{\xi_{i}}$ 's. For example, the $\mathrm{g}^{+} \mathrm{g}^{+} \mathrm{g}^{+}$conformation has a weight

Table I. SCF $(\Delta \mathrm{SCF})$ and free $\left(\Delta G_{k}\right)$ energies of conformers of $\mathrm{DME}^{\mathrm{a}}$

\begin{tabular}{rccccc}
\hline$k$ & conformation & $M_{k}$ & $\begin{array}{c}\text { statistical } \\
\text { weight }\end{array}$ & $\begin{array}{c}\Delta \mathrm{SCF}^{\mathrm{c}} \\
\left(\mathrm{kcal} \mathrm{mol}^{-1}\right)\end{array}$ & $\begin{array}{c}\Delta G_{k}{ }^{\mathrm{c}} \\
\left(\mathrm{kcal} \mathrm{mol}^{-1}\right)\end{array}$ \\
\hline 1 & $\mathrm{ttt}$ & 1 & 1 & 0.00 & 0.00 \\
2 & $\operatorname{ttg}^{ \pm}$ & 4 & $\rho_{2}$ & 1.49 & 1.31 \\
3 & $\operatorname{tg}^{ \pm} \mathrm{t}$ & 2 & $\sigma_{3}$ & 0.20 & 0.19 \\
4 & $\operatorname{tg}^{ \pm} \mathrm{g}^{ \pm}$ & 4 & $\rho_{2} \sigma_{3}$ & 1.61 & 1.28 \\
5 & $\operatorname{tg}^{ \pm} \mathrm{g}^{\mp}$ & 4 & $\rho_{2} \sigma_{3} \omega_{3}$ & 0.38 & 0.26 \\
6 & $\mathrm{~g}^{ \pm} \mathrm{tg}^{ \pm}$ & 2 & $\rho_{2}^{2}$ & 3.05 & 2.74 \\
7 & $\mathrm{~g}^{ \pm} \operatorname{tg}^{\mp}$ & 2 & $\rho_{2}^{2}$ & 3.00 & 2.61 \\
8 & $\mathrm{~g}^{ \pm} \mathrm{g}^{ \pm} \mathrm{g}^{ \pm}$ & 2 & $\rho_{2}^{2} \sigma_{3} \chi_{4}$ & 1.73 & 2.27 \\
9 & $\mathrm{~g}^{ \pm} \mathrm{g}^{ \pm} \mathrm{g}^{\mp}$ & 4 & $\rho_{2}^{2} \sigma_{3} \omega_{3}$ & 1.97 & 1.88 \\
10 & $\mathrm{~g}^{ \pm} \mathrm{g}^{\mp} \mathrm{g}^{ \pm}$ & 2 & $\rho_{2}^{2} \sigma_{3} \omega_{3}^{2}$ & 2.32 & 1.77 \\
\hline
\end{tabular}

${ }^{\text {a }}$ Relative to the all-trans conformation. At $25^{\circ} \mathrm{C}$ and $1 \mathrm{~atm}$. ${ }^{\mathrm{b}}$ For the statistical weights, see eqs $1-5$ and Figure 2. ${ }^{\mathrm{c}}$ At the MP2/6-311++G(3df, 3pd)//HF/6-31G(d) level.
Table II. SCF $(\triangle \mathrm{SCF})$ and free $\left(\Delta G_{k}\right)$ energies of conformers of triglyme ${ }^{\mathrm{a}}$

\begin{tabular}{rcccc}
\hline$k$ & gauche bond(s) & $\begin{array}{c}\text { statistical } \\
\text { weight }\end{array}$ & $\begin{array}{c}\Delta \mathrm{SCF}^{\mathrm{c}} \\
\left(\mathrm{kcal} \mathrm{mol}^{-1}\right)\end{array}$ & $\begin{array}{c}\Delta G_{k}{ }^{\mathrm{c}} \\
\left(\mathrm{kcal} \mathrm{mol}^{-1}\right)\end{array}$ \\
\hline 1 & none (all-trans) & 1 & 0.00 & 0.00 \\
2 & 2 & $\rho_{2}$ & 1.45 & 1.25 \\
3 & 3 & $\sigma_{3}$ & 0.03 & 0.06 \\
4 & 4 & $\rho_{4}$ & 1.27 & 1.09 \\
5 & 5 & $\rho_{5}$ & 1.23 & 1.05 \\
6 & 6 & $\sigma_{6}$ & -0.13 & -0.08 \\
7 & $2\left(\mathrm{~g}^{ \pm}\right) 3\left(\mathrm{~g}^{\mp}\right)$ & $\rho_{2} \sigma_{3} \omega_{3}$ & 0.28 & 0.15 \\
8 & $3\left(\mathrm{~g}^{ \pm}\right) 4\left(\mathrm{~g}^{\mp}\right)$ & $\sigma_{3} \rho_{4} \omega_{4}$ & 0.19 & -0.03 \\
9 & $5\left(\mathrm{~g}^{ \pm}\right) 6\left(\mathrm{~g}^{\mp}\right)$ & $\rho_{5} \sigma_{6} \omega_{6}$ & 0.04 & -0.18 \\
10 & $2\left(\mathrm{~g}^{ \pm}\right) 3\left(\mathrm{~g}^{ \pm}\right) 4\left(\mathrm{~g}^{ \pm}\right)$ & $\rho_{2} \sigma_{3} \rho_{4} \chi_{4}$ & 1.42 & 1.95 \\
11 & $5\left(\mathrm{~g}^{ \pm}\right) 6\left(\mathrm{~g}^{ \pm}\right) 7\left(\mathrm{~g}^{ \pm}\right)$ & $\rho_{5}^{2} \sigma_{6} \chi_{7}$ & 1.12 & 1.64 \\
\hline
\end{tabular}

${ }^{\text {a }}$ Relative to the all-trans conformation. At $25^{\circ} \mathrm{C}$ and $1 \mathrm{~atm}$. ${ }^{\mathrm{b}}$ For the statistical weights, see eqs $1-5$ and Figure $2 .{ }^{\mathrm{c}}$ At the MP2/6-311++G(3df, 3pd)//HF/6-31G(d) level.

of $\rho_{2}^{2} \sigma_{3} \chi_{4}$. Thus, the $\Delta G_{k}$ value may correspond to $2 E_{\rho_{2}}+E_{\sigma_{3}}+E_{\chi_{4}}$. The statistical weight is related to the corresponding conformational energy through the Boltzmann factor; for example, $\rho=\exp \left(-E_{\rho} / R T\right)$, where $R$ is the gas constant, and $T$ is the absolute temperature. The $E_{\xi}$ values were determined by minimizing the following function:

$$
\begin{aligned}
S(\mathbf{E})= & \frac{1}{K} \sum_{k}\left(\sum_{\xi} L(\xi) E_{\xi}-\Delta G_{k}\right)^{2} \\
& \times M_{k} \exp \left(-\Delta G_{k} / R T\right)
\end{aligned}
$$

The function $L(\xi)$ gives the number of conformational energy $E_{\xi}$ included in the conformation, $K$ is the total number of conformers, and $M_{k}$ is the number of equivalent conformers. The squared difference between $\Delta G_{k}$ and the sum of $E_{\xi}$ 's was multiplied by the Boltzmann factor $\exp \left(-\Delta G_{k} / R T\right)$ so as to weight low-energy conformations. The temperature was set to $298.15 \mathrm{~K}$. The $E_{\xi}$ values were determined as shown in Table III. The positive $E_{\sigma_{3}}$ value of DME indicates that the ttt state is slightly more stable than tgt. For tri-

Table III. Conformational energies of DME and triglyme ${ }^{\mathrm{a}}$

\begin{tabular}{ccc}
\hline & DME & triglyme \\
\hline$E_{\rho_{2}}$ & 1.30 & 1.25 \\
$E_{\rho_{4}}$ & & 1.09 \\
$E_{\rho_{5}}$ & & 1.05 \\
$E_{\sigma_{3}}$ & 0.08 & 0.06 \\
$E_{\sigma_{6}}$ & & -0.08 \\
$E_{\omega_{3}}$ & -1.02 & -1.15 \\
$E_{\omega_{4}}$ & & -1.18 \\
$E_{\omega_{6}}$ & & -1.14 \\
$E_{\chi_{4}}$ & -0.42 & -0.44 \\
$E_{\chi_{7}}$ & & -0.37 \\
\hline
\end{tabular}

${ }^{\mathrm{a}}$ In $\mathrm{kcal} \mathrm{mol}^{-1}$. 


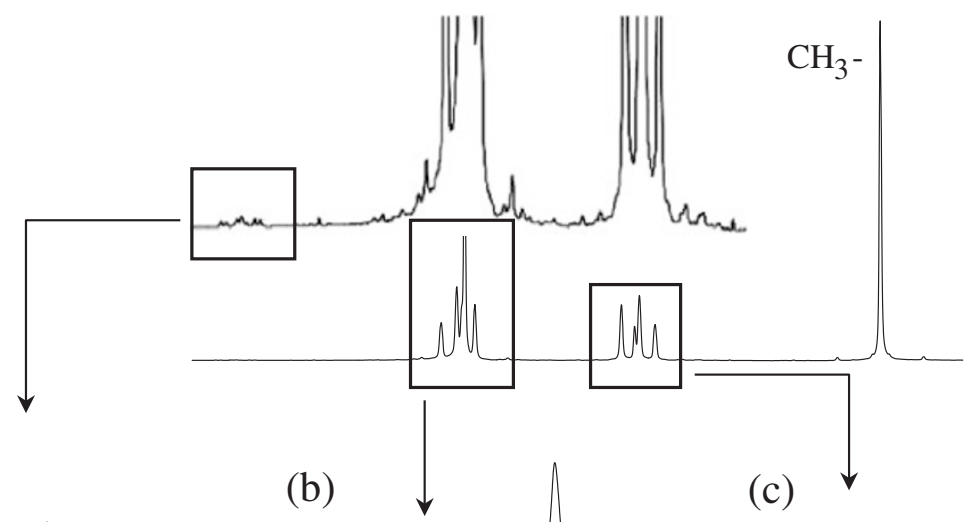

(a)
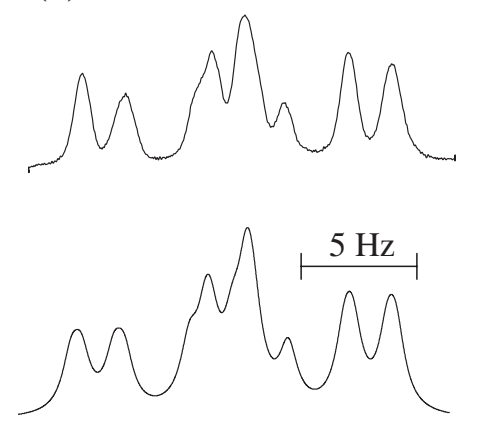

(b)
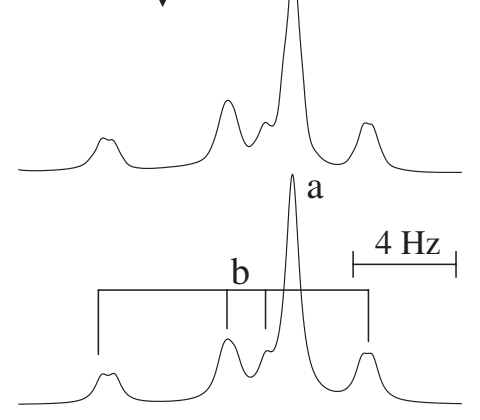

(c)
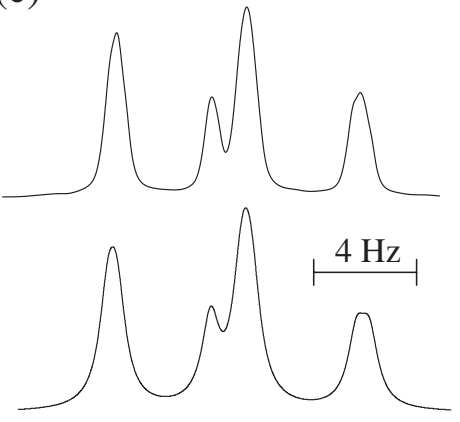

Figure 3. Observed (above) and calculated (below) ${ }^{1} \mathrm{H}$ NMR spectra of triglyme dissolved in cyclohexane- $d_{12}$ at $25^{\circ} \mathrm{C}$ : (a) methylene group a (satellite peaks); (b) methylene groups a and b; (c) methylene group c. For the designation of protons, see Figure 1.

glyme, the MO calculations were so time-consuming as to be performed only for specific conformers. From the $\Delta G_{k}$ values, the $E_{\xi_{i}}$ values were derived for the individual bonds as listed in Table III.

The results can be summarized as follows. (1) A narrow range $\left(-1.02\right.$ to $\left.-1.18 \mathrm{kcal} \mathrm{mol}^{-1}\right)$ of $E_{\omega}$ 's were obtained for the two model compounds, the strength of the intramolecular hydrogen bond may scarcely depend on the chain length and position. (2) The $E_{\sigma_{3}}$ and $E_{\sigma_{6}}$ values are slightly positive and negative, respectively; the terminal monomeric unit has an $E_{\sigma}$ value larger than the inner one. This suggests the possibility that PEO can adopt the gauche conformation in the $\mathrm{C}-\mathrm{C}$ bond without the aid of the intramolecular hydrogen bonds; therefore, as a single chain, PEO somewhat prefers the helical structure to the all-trans planar zigzag form. The all-trans PEO chains, whose zigzag planes are parallel to each other, are packed in a $P_{\overline{1}}$ triclinic lattice. ${ }^{14}$ Densities of the monoclinic (helix) and triclinic (zigzag) lattices are 1.228 and $1.197 \mathrm{~g} \mathrm{~cm}^{-3}$, respectively; therefore, the helical chains are more densely packed than the planar zigzag ones. The small magnitude of $E_{\sigma_{6}}$ suggests that PEO may change the $\mathrm{C}-\mathrm{C}$ conformation between gauche and trans even in the crystal.

\section{${ }^{1}$ H NMR of Triglyme}

Figure 3 shows an example of ${ }^{1} \mathrm{H}$ NMR spectra observed from methylene protons of triglyme. Simu- lations using the gNMR program ${ }^{19}$ yielded vicinal coupling constants, ${ }^{3} J_{\mathrm{HH}}\left(={ }^{3} J_{\mathrm{AB}}={ }^{3} J_{\mathrm{A}^{\prime} \mathrm{B}^{\prime}}\right)$ and ${ }^{3} J_{\mathrm{HH}}^{\prime}$ $\left(={ }^{3} J_{\mathrm{AB}^{\prime}}={ }^{3} J_{\mathrm{A}^{\prime} \mathrm{B}}\right)$, as listed in Table IV. The observed coupling constants can be expressed as

$$
{ }^{3} J_{\mathrm{HH}}={ }^{3} J_{\mathrm{G}} p_{\mathrm{t}}+\frac{{ }^{3} J_{\mathrm{T}}^{\prime}+{ }^{3} J_{\mathrm{G}}^{\prime \prime}}{2} p_{\mathrm{g}}
$$

and

$$
{ }^{3} J_{\mathrm{HH}}^{\prime}={ }^{3} J_{\mathrm{T}} p_{\mathrm{t}}+{ }^{3} J_{\mathrm{G}}^{\prime} p_{\mathrm{g}}
$$

where ${ }^{3} J_{\mathrm{T}}$ 's and ${ }^{3} J_{\mathrm{G}}$ 's are defined in Figure 4 , and $p_{\mathrm{t}}$ and $p_{\mathrm{g}}$ are trans and gauche fractions of the $\mathrm{C}-\mathrm{C}$ bond, respectively; therefore, $p_{\mathrm{t}}+p_{\mathrm{g}}=1$. Here, we have adopted ${ }^{3} J$ values optimized for DME: ${ }^{3} J_{\mathrm{T}}=$ ${ }^{3} J_{\mathrm{T}}^{\prime}=11.4 \mathrm{~Hz}$ and ${ }^{3} J_{\mathrm{G}}={ }^{3} J_{\mathrm{G}}^{\prime}={ }^{3} J_{\mathrm{G}}^{\prime \prime}=2.3 \mathrm{~Hz}$. ${ }^{7}$ The sum of $p_{\mathrm{t}}$ and $p_{\mathrm{g}}$ values derived from eqs 7 and 8 was only slightly different from unity, thus being divided by the sum. In Table IV, the $p_{\mathrm{t}}$ and $p_{\mathrm{g}}$ values of bonds 3 and 6 are compared with those evaluated from the MO calculations. In general, the trans fraction decreases with increasing permittivity of the environment. This tendency agrees with that found previously for DME. ${ }^{7}$

As outlined in the Introduction, $E_{\sigma_{i}}$ 's and $E_{\omega_{i}}$ 's tend to vary cooperatively with the medium. Increases in $E_{\omega_{i}}$ 's with increaseing permittivity of the medium are compensated by decreases in $E_{\sigma_{i}}$ 's. Consequently, the bond conformations do not show large variations, and hence the three kinds of energy parameters, $E_{\sigma_{i}}$ 's, $E_{\omega_{i}}$ 's, and $E_{\rho_{i}}$ 's, can not be determined only from $p_{\mathrm{t}}$ 
The Attractive Gauche Effect of Ethylene Oxides

Table IV. Vicinal ${ }^{1} \mathrm{H}-{ }^{1} \mathrm{H}$ coupling constants and bond conformations of triglyme at $25^{\circ} \mathrm{C}$

\begin{tabular}{|c|c|c|c|c|c|c|c|c|c|}
\hline \multirow[b]{2}{*}{ solvent } & \multirow[b]{2}{*}{ permittivity } & \multicolumn{4}{|c|}{ bond 3} & \multicolumn{4}{|c|}{ bond 6} \\
\hline & & ${ }^{3} J_{\mathrm{HH}}$ & ${ }^{3} J_{\mathrm{HH}}^{\prime}$ & $p_{\mathrm{t}}$ & $p_{\mathrm{g}}$ & ${ }^{3} J_{\mathrm{HH}}$ & ${ }^{3} J_{\mathrm{HH}}^{\prime}$ & $p_{\mathrm{t}}$ & $p_{\mathrm{g}}$ \\
\hline \multicolumn{10}{|c|}{ MO calc ${ }^{\mathrm{a}}$} \\
\hline (gas) & 1.0 & & & 0.21 & 0.79 & & & 0.17 & 0.83 \\
\hline \multicolumn{10}{|c|}{ NMR exptl } \\
\hline cyclohexane- $d_{12}$ & 2.0 & 6.01 & 4.30 & 0.21 & 0.79 & 6.10 & 4.03 & 0.18 & 0.82 \\
\hline chloroform- $d$ & 4.8 & 6.25 & 3.30 & 0.11 & 0.89 & 6.30 & 3.43 & 0.12 & 0.88 \\
\hline methanol- $d_{4}$ & 32.7 & 6.27 & 3.31 & 0.11 & 0.89 & 6.21 & 3.27 & 0.11 & 0.89 \\
\hline dimethyl sulfoxide- $d_{6}$ & 46.7 & 6.30 & 3.48 & 0.13 & 0.87 & 6.24 & 3.44 & 0.13 & 0.87 \\
\hline deuterium oxide & 78.5 & 6.42 & 2.66 & 0.05 & 0.95 & 6.36 & 2.62 & 0.05 & 0.95 \\
\hline
\end{tabular}

${ }^{a}$ Evaluated from the conformational energies shown in Table III.

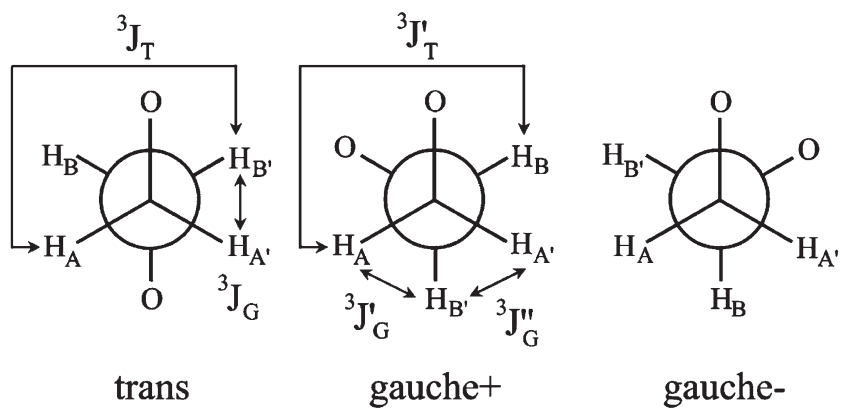

Figure 4. Conformations around the $\mathrm{C}-\mathrm{C}$ bond of the ethylene oxides with definitions of vicinal coupling constants.

values of bonds 3 and 6; therefore, we have assumed $E_{\omega_{i}}$ and $E_{\rho_{i}}$ values as follows to derive $E_{\sigma_{3}}$ and $E_{\sigma_{6}}$ of triglyme.

The boiling point of triglyme is so high $\left(216^{\circ} \mathrm{C}\right)$ that NMR measurement for gaseous triglyme could not be conducted. In the previous study on $\mathrm{DME},{ }^{20}$ the ${ }^{3} J_{\mathrm{HH}}$ and ${ }^{3} J_{\mathrm{HH}}^{\prime}$ versus temperature plots for the gas phase and the cyclohexane solution overlap with each other, and no discontinuity was found between the two kinds of data. In fact, as seen from Table IV, the $p_{\mathrm{t}}$ and $p_{\mathrm{g}}$ values for the cyclohexane solution at $25^{\circ} \mathrm{C}$ agree with those of the MO calculations for gaseous triglyme at $25^{\circ} \mathrm{C}$. In Figure 5, the $p_{\mathrm{t}}$ values, calculated from $E_{\xi_{i}}$ 's (Table III) of triglyme except for $E_{\sigma_{6}}$, are plotted as a function of $E_{\sigma_{6}}$ (curve A). The curve intersects with the horizontal line for the cyclohexane solution around $E_{\sigma_{6}}=-0.1 \mathrm{kcal} \mathrm{mol}^{-1}$. This value probably corresponds to $E_{\sigma_{6}}$ of not only the cyclohexane solution but also the gas phase. From bond conformations of PEO dissolved in 1,4-dioxane and dipole moment ratios for the benzene solution, we determined $E_{\rho}=1.17$ and $E_{\omega}=-0.79 \mathrm{kcal} \mathrm{mol}^{-1}$. $^{3}$ These energy parameters are considered to represent the ethylene oxides in weakly polar solvents. From $E_{\rho_{i}}{ }^{\prime} \mathrm{s}=1.17, E_{\omega_{i}}{ }^{\prime} \mathrm{s}=-0.79 \mathrm{kcal} \mathrm{mol}^{-1}$, and $E_{\sigma_{3}}=$ $E_{\sigma_{6}}$, the $p_{\mathrm{t}}$ values were calculated and plotted against $E_{\sigma_{6}}$ (curve B). Similarly, curve C was obtained from

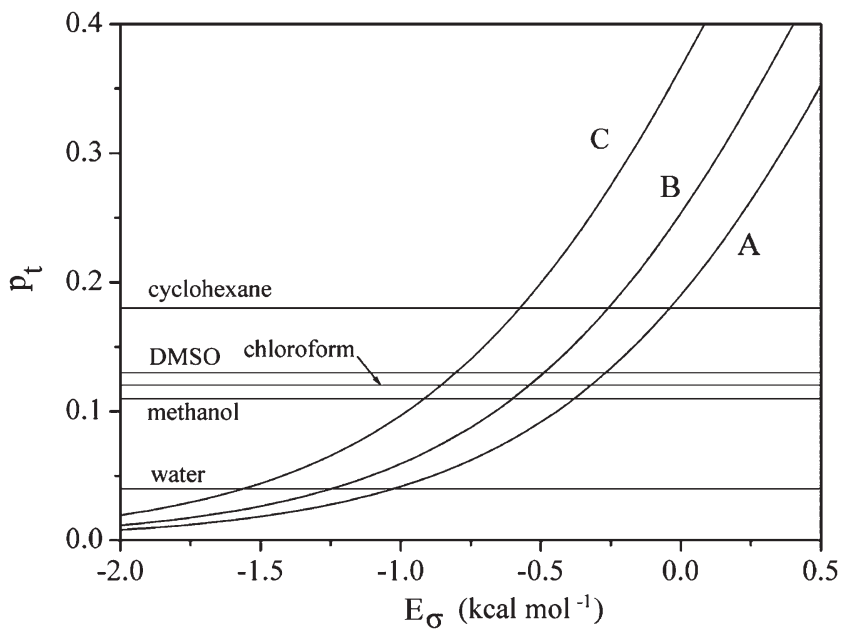

Figure 5. Trans fraction $\left(p_{\mathrm{t}}\right)$ of bond 6 of triglyme as a function of $E_{\sigma_{6}}$. The horizontal lines represent the $p_{\mathrm{t}}$ values determined from the NMR experiments using the solvents indicated. Curves $\mathrm{A}, \mathrm{B}$, and $\mathrm{C}$ were obtained from the following energy parameters: curve A, conformational energies of triglyme in Table III, except for $E_{\sigma_{6}}$; curve $\mathrm{B}, E_{\rho_{i}}$ 's $=1.17$ and $E_{\omega_{i}}$ 's = $-0.79 \mathrm{kcal} \mathrm{mol}^{-1} ; \quad$ curve C, $\quad E_{\rho_{i}}{ }^{\prime} \mathrm{s}=0.9 \quad$ and $\quad E_{\omega_{i}}{ }^{\prime} \mathrm{s}=0.4$ $\mathrm{kcal} \mathrm{mol}{ }^{-1}$. For curves B and C, $E_{\sigma_{3}}=E_{\sigma_{6}}$ was assumed.

$E_{\rho_{i}}{ }^{\prime} \mathrm{s}=0.9$ and $E_{\omega_{i}}{ }^{\prime} \mathrm{s}=0.4 \mathrm{kcal} \mathrm{mol}^{-1}$ (the $\Theta$ solution of PEO, i.e., $0.45 \mathrm{M} \mathrm{K}_{2} \mathrm{SO}_{4}$ at $34.5^{\circ} \mathrm{C}$ ). The horizontal lines for chloroform, dimethyl sulfoxide, and methanol intersect with curves $\mathrm{B}$ and $\mathrm{C}$ around $E_{\sigma_{6}}=$ -0.5 and -0.8 to $-0.9 \mathrm{kcal} \mathrm{mol}^{-1}$, respectively. Therefore, the $E_{\sigma_{6}}$ values of triglyme in these solvents probably stay within the range. From the intersection between curve $\mathrm{C}$ and the horizontal line of water, we can estimate the $E_{\sigma_{6}}$ value of triglyme in water as $\leq-1.6 \mathrm{kcal} \mathrm{mol}^{-1}$.

From the $p_{\mathrm{t}}$ versus $E_{\sigma_{3}}$ plots (not shown), we similarly estimated the $E_{\sigma_{3}}$ values of bond 3 of triglyme in the solvents: cyclohexane, $+0.1 \mathrm{kcal} \mathrm{mol}^{-1}$; chloroform, methanol, and dimethyl sulfoxide, -0.5 to $-0.9 \mathrm{kcal} \mathrm{mol}^{-1}$; water, $\leq-1.4 \mathrm{kcal} \mathrm{mol}^{-1}$. Both MO calculations and NMR experiments indicate that $E_{\sigma_{6}}$ of triglyme is negative even in the gas phase. How- 
ever, the essential fact here is that $E_{\sigma_{6}}$ is significantly smaller than $E_{\sigma}\left(+0.5 \mathrm{kcal} \mathrm{mol}^{-1}\right)$ of hydrocarbon chains ${ }^{5,21}$ because this indicates the inherent gauche stability of the $\mathrm{C}-\mathrm{C}$ bond adjacent to the ether linkage, i.e., the attractive gauche effect independent of the $(\mathrm{C}-\mathrm{H}) \cdots \mathrm{O}$ attraction.

Finally, the small differences in $E_{\xi}$ 's between DME and triglyme (Table III) fairly justify conformational analyses of polymers using monomeric model compounds, unless very strict discussion is required.

Acknowledgment. This work was partly supported by the Asahi Glass Foundation and a Grant-in-Aid for Scientific Research (B) (18350112) from the Japan Society for the Promotion of Science.

\section{REFERENCES}

1. E. Juaristi, "Introduction to Stereochemistry and Conformational Analysis," Wiley \& Sons, New York, 1991, chap. 18.

2. E. Juaristi and G. Cuevas, "The Anomeric Effect," CRC Press, Boca Raton, FL, 1995, chap. 4.

3. Y. Sasanuma, H. Ohta, I. Touma, H. Matoba, Y. Hayashi, and A. Kaito, Macromolecules, 35, 3748 (2002).

4. J. E. Mark and P. J. Flory, J. Am. Chem. Soc., 87, 1415 (1965).

5. P. J. Flory, "Statistical Mechanics of Chain Molecules," Wiley \& Sons, New York, 1969.

6. A. Abe and J. E. Mark, J. Am. Chem. Soc., 98, 6468 (1976).

7. K. Tasaki and A. Abe, Polym. J., 17, 641 (1985).

8. D. T. Baldwin, W. L. Mattice, and R. D. Gandour, J. Comput. Chem., 5, 241 (1984).

9. A. Abe, H. Furuya, M. K. Mitra, and T. Hiejima, Comput. Theor. Polym. Sci., 8, 253 (1998).

10. G. D. Smith, D. Bedrov, and O. Borodin, J. Am. Chem. Soc., 122, 9548 (2000).

11. A. E. Reed, L. A. Curtiss, and F. Weinhold, Chem. Rev., 88, 899 (1988).
12. H. Tadokoro, Y. Chatani, T. Yoshihara, S. Tahara, and S. Murahashi, Makromol. Chem., 73, 109 (1964).

13. Y. Takahashi and H. Tadokoro, Macromolecules, 6, 672 (1973).

14. Y. Takahashi, I. Sumita, and H. Tadokoro, J. Polym. Sci., Polym. Phys. Ed., 11, 2113 (1973).

15. K. Tashiro and H. Tadokoro, Rep. Prog. Polym. Phys. Jpn., 21, 417 (1978).

16. M. J. Frisch, G. W. Trucks, H. B. Schlegel, G. E. Scuseria, M. A. Robb, J. R. Cheeseman, J. A. Montgomery, Jr., T. Vreven, K. N. Kudin, J. C. Burant, J. M. Millam, S. S. Iyengar, J. Tomasi, V. Barone, B. Mennucci, M. Cossi, G. Scalmani, N. Rega, G. A. Petersson, H. Nakatsuji, M. Hada, M. Ehara, K. Toyota, R. Fukuda, J. Hasegawa, M. Ishida, T. Nakajima, Y. Honda, O. Kitao, H. Nakai, M. Klene, X. Li, J. E. Knox, H. P. Hratchian, J. B. Cross, V. Bakken, C. Adamo, J. Jaramillo, R. Gomperts, R. E. Stratmann, O. Yazyev, A. J. Austin, R. Cammi, C. Pomelli, J. W. Ochterski, P. Y. Ayala, K. Morokuma, G. A. Voth, P. Salvador, J. J. Dannenberg, V. G. Zakrzewski, S. Dapprich, A. D. Daniels, M. C. Strain, O. Farkas, D. K. Malick, A. D. Rabuck, K. Raghavachari, J. B. Foresman, J. V. Ortiz, Q. Cui, A. G. Baboul, S. Clifford, J. Cioslowski, B. B. Stefanov, G. Liu, A. Liashenko, P. Piskorz, I. Komaromi, R. L. Martin, D. J. Fox, T. Keith, M. A. Al-Laham, C. Y. Peng, A. Nanayakkara, M. Challacombe, P. M. W. Gill, B. Johnson, W. Chen, M. W. Wong, C. Gonzalez, and J. A. Pople, Gaussian 03, Revision C.02, Gaussian, Inc., Wallingford CT, 2004.

17. J. A. Pople, A. P. Scott, M. W. Wong, and L. Radom, Isr. J. Chem., 33, 345 (1993).

18. W. L. Mattice and U. W. Suter, "Conformational Theory of Large Molecules: The Rotational Isomeric State Model in Macromolecular Systems," Wiley \& Sons, New York, 1994.

19. P. H. M. Budzelaar, "gNMR, version 5.0," IvorySoft \& Adept Scientific plc, Letchworth, U.K., 2004.

20. K. Inomata and A. Abe, J. Phys. Chem., 96, 7934 (1992).

21. A. Abe, R. L. Jernigan, and P. J. Flory, J. Am. Chem. Soc., 88, 631 (1966). 